\title{
Acceptance and practicability of a visual communication tool in smoking cessation counselling: a randomised controlled trial
}

\author{
*Stefan Neuner-Jehle ${ }^{1,4}$, Marianne I Knecht ${ }^{1}$, Claudia Stey-Steurer ${ }^{1,2,3}$, Oliver Senn ${ }^{1,2}$ \\ ${ }^{1}$ Institute of General Practice and Health Services Research, University of Zürich, Switzerland \\ ${ }^{2}$ Medical Practice, Zürich, Switzerland \\ ${ }^{3}$ Medix $\mathrm{HMO}$, Switzerland \\ ${ }^{4}$ Medical Practice, Zug, Switzerland
}

Originally received 22nd March 2013; resubmitted 18th June 2013; revised 3rd July 2013; further revision 5th July 2013; accepted 5th July 2013; online 7th October 2013

\begin{abstract}
Background: Smoking cessation advice is important for reducing the worldwide burden of disease resulting from tobacco smoking. Appropriate risk communication formats improve the success of counselling interventions in primary care.

Aims: To test the feasibility and acceptance of a smoking cessation counselling tool with different cardiovascular risk communication formats including graphs, in comparison with the International Primary Care Respiratory Group (IPCRG) 'quit smoking assistance' tool.

Methods: GPs were randomised into an intervention group (using our communication tool in addition to the IPCRG sheet) and a control group (using the IPCRG sheet only). We asked participants for socioeconomic data, smoking patterns, understanding of information, motivation, acceptance and feasibility, and measured the duration and frequency of counselling sessions.

Results: Twenty-five GPs performed 2.8 counselling sessions per month in the intervention group and 1.7 in the control group ( $p=0.3$ ) with 114 patients. The median duration of a session was 10 mins (control group 11 mins, p=0.09 for difference). Median patients' motivation for smoking cessation was 7 on a 10-point visual analogue scale with no significant difference before and after the intervention ( $p=0.2$ ) or between groups ( $p=0.73$ before and $p=0.15$ after the intervention). Median patients' ratings of motivation, selfconfidence, understanding of information, and satisfaction with the counselling were 3-5 on a 5-point Likert scale, similar to GPs' ratings of acceptance and feasibility, with no significant difference between groups.
\end{abstract}

Conclusions: Among Swiss GPs and patients, both our innovative communication tool and the IPCRG tool were well accepted and both merit further dissemination and application in research.

(C) 2013 Primary Care Respiratory Society UK. All rights reserved.

S Neuner-Jehle et al. Prim Care Respir J 2013; 22(4): 412-416

http://dx.doi.org/10.4104/pcrj.2013.00086

Keywords risk communication, motivational interviewing, tobacco smoking cessation, short intervention, family medicine

\section{See linked editorial by Lewis on pg 387}

The full version of this paper, with online appendices,

is available online at www.thepcrj.org

\section{Introduction}

Tobacco smoking is a significant public health problem. About half of all persistent cigarette smokers are killed by their habit - a quarter while still in middle age - with an estimated mortality worldwide of 5,000,000 per year. ${ }^{1-4}$ According to the World Health Organization, smoking is the leading preventable cause of death worldwide. ${ }^{3}$ Compared with non-smokers, the relative risk of a smoker developing cardiovascular disease (CVD) is 1.6-3.0, of suffering a stroke is 1.8-4.8, and of developing lung or oropharyngeal cancer is 17.8-22.3, dependent on age and gender.' However, the incidence (absolute risk) of malignant disease due to smoking is considerably lower than that of CVD as a potential long-term consequence of smoking.

\footnotetext{
* Corresponding author: Dr Stefan Neuner-Jehle, Institute of General Medicine and Health Services Research, University of Zürich, Pestalozzistrasse 24, 8091 Zürich, Switzerland. Tel: +41 417110988 Fax: +417110980 E-mail: sneuner@bluewin.ch
} 
In a recent survey in Switzerland the proportion of smokers in the population was $27 \%$, similar to the last decade. ${ }^{5}$ Half of the smokers who consider quitting are either in a contemplation state or in a preparation state according to the transtheoretical model (TTM) of changing behaviour., ${ }^{5,6}$ In this process of reconsidering, motivation and self-efficacy are independent predictors of success. ${ }^{7}$ As the majority of Swiss smokers (84\%) discussed smoking cessation issues with their general practitioners (GPs), ${ }^{5}$ GPs are important key players in the effort to reduce the proportion of smokers in a population. A short smoking cessation intervention from the GP based on the individual smoker's motivational state helps patients to quit ${ }^{8}$ and is therefore an important and relevant method of reducing the hazards associated with smoking.

In patient counselling, communication tools (particularly visual aids) and motivational interviewing techniques improve the success of interventions aimed at behaviour change. ${ }^{9-12}$ We therefore developed a smoking cessation counselling tool which integrates visual aids and facilitates motivational interviewing techniques. Based on the International Primary Care Respiratory Group (IPCRG) 'quit smoking assistance' tool and the counselling process, ${ }^{13}$ we added some relevant risk information about smoking. To translate CVD risks, we used a combination of communication formats (verbal, numerical, visual) and focused on the benefits to the patient (risk reduction) of smoking cessation. The IPCRG tool was used as the reference standard and we hypothesised that our tool is not inferior to the IPCRG tool with regard to feasibility and acceptance.

\section{Methods}

\section{Development of the tool: choice of outcome (risk) to communicate}

We chose CVD morbidity as the main risk communication issue for our tool in order to achieve maximal motivation. We calculated the absolute 10-year risk for cardiovascular events for smokers aged 35-65 years versus non-smokers of the same age using the risk calculator of the Swiss Task Force on Lipids and Atherosclerosis (www.agla.ch), ${ }^{14}$ which uses the database of the PROCAM cohort. ${ }^{15}$ Risk calculation by this tool requires age, gender, menopausal state, total serum cholesterol, serum HDL, serum triglycerides, diabetes, and family history. Our intention was to perform the counselling tool as a short intervention and as time-sparingly as possible. On the other hand, we wanted to perform individualised counselling based on the individual risk situation of each patient. Therefore, in order to avoid time-consuming data sampling from patients, we assumed gender-specific average values for most of the required cardiovascular risk factors based on the representative populationbased Swiss cohort study SAPALDIA. ${ }^{16}$ Thus, GPs only had to define gender, age, and smoking state of the patients to assess the individualised cardiovascular risk, which was possible to do within a few seconds (see Appendix 1, available online at www.thepcrj.org).

In our tool, risks are shown numerically with absolute percentages, relative percentages and natural frequencies, and visually with colour-coded bar charts (see Appendix 2, available online at www.thepcrj.org). Additionally, the age-related cardiovascular risk of a smoker is communicated in relation to the age of a non-smoker with the equivalent risk (organ age risk communication format, analogous to the lung age concept ${ }^{12}$ ). In order to standardise the 'usual' counselling interventions for tobacco smoking cessation, all participating GPs used the recommended Opinion Sheet for smoking cessation of the IPCRG ${ }^{13}$ (see Appendix 3, available online at www.thepcrj.org) which is using motivational interviewing techniques.

\section{Study protocol}

The 27 participating GPs were randomised into an intervention group using our communication tool in addition to the IPCRG sheet, and a control group using the IPCRG sheet only. All study GPs underwent a group instruction. After a run-in period of two months to assess the frequency of usual counselling activity, the study period was six months. In each practice the GPs included up to 10 consecutive smokers aged 20-80 years. Exclusion criteria were a short life expectancy ( $<10$ years), cognitive impairment, or any acute disease.

\section{Table 1. Baseline characteristics}

\begin{tabular}{|c|c|c|c|c|}
\hline Characteristic & Median & IQR & Number & $\begin{array}{l}\% \text { of } \\
\text { cases }\end{array}$ \\
\hline \multicolumn{5}{|l|}{$\begin{array}{l}\text { Physician characteristics } \\
\left(n=27^{*}\right)\end{array}$} \\
\hline Age, years & 48 & $43-55$ & & \\
\hline Experience as a GP, years & 10 & 4-19 & & \\
\hline $\begin{array}{l}\text { Workload, percentage } \\
(100 \%=5 \text { days working/week) }\end{array}$ & 100 & 60-100 & & \\
\hline Sex, males & & & 14 & 52.9 \\
\hline Practice type, solo & & & 9 & 33.3 \\
\hline $\begin{array}{l}\text { No. of patients counselled } \\
\text { per GP }\end{array}$ & 4 & $2-7$ & & \\
\hline \multicolumn{5}{|l|}{$\begin{array}{l}\text { Patient characteristics } \\
(n=114)\end{array}$} \\
\hline Age, years & 47 & $33-57$ & & \\
\hline Sex, male & & & 60 & 50.9 \\
\hline Education level, primary & & & 12 & 10.2 \\
\hline secondary & & & 67 & 56.8 \\
\hline high school & & & 11 & 9.3 \\
\hline academic & & & 28 & 23.7 \\
\hline $\begin{array}{l}\text { Age at the begin of smoking, } \\
\text { years }\end{array}$ & 17 & $15-20$ & & \\
\hline Duration of smoking, years & 29 & $15-38$ & & \\
\hline \multirow[t]{6}{*}{ Cigarettes per day } & & & 4 & 3.4 \\
\hline & & & 23 & 19.5 \\
\hline & & & 18 & 15.3 \\
\hline & & & 39 & 33.1 \\
\hline & & & 18 & 15.3 \\
\hline & & & 16 & 13.6 \\
\hline No attempts to quit & & & 74 & 64.4 \\
\hline $\begin{array}{l}\text { Partner smoking (n with } \\
\text { partner=67) }\end{array}$ & & & 31 & 46.3 \\
\hline
\end{tabular}




\section{Measurements}

Patient data on socioeconomics, smoking history, smoking patterns, comprehensiveness of the information, satisfaction, self-confidence, acceptance, and feasibility were collected by a questionnaire using a 5-point Likert scale. Patients rated their motivation before and after the intervention on a 10-point numerical visual analogue scale (VAS). GPs measured counselling duration and frequency as a proxy for acceptance and were asked about their estimates of acceptance and practicability of the tool by a short questionnaire.

\section{Statistics}

We defined a difference in counselling frequency between the intervention and control groups of $\leq 20 \%$ as suggesting noninferiority of the tool compared with usual care. Data are presented as median (IQR) and frequencies. Patient and counselling characteristics were compared between the intervention and control groups using Wilcoxon tests. In addition, a modified Wilcoxon rank sum test ${ }^{17}$ was applied to account for the potential cluster dependence at the GP level. A two-sided alpha level of 0.05 was assumed to indicate significance. The analyses were performed using Stata ${ }^{\circledR}$ Version 12.1 (Stata Corporation, College Station, Texas, USA; www.stata.com).

All patients gave written informed consent and the study was approved by the local ethics committee of Zurich.

\section{Results}

The characteristics of the GPs and patients are shown in Table 1. On average (medians), GPs had 10 years' practice experience; two-thirds of them were working in group practices. The average patient had been a smoker since the age of 17 and for almost 30 years. One-third of patients had not tried to quit smoking before and half of the patients had partners who smoked. The prevalence of comorbidities in our study population was equal to the average Swiss practice population (data not shown).

Detailed group comparisons of counselling and tool characteristics are shown in Table 2. During the 6-month study period, 25 GPs performed 2.8 (IQR 1.7-4.2) counselling sessions per month in the intervention group and 1.7 (IQR 1.3-3.3) in the control group ( $p=0.3$ ), with a total of 114 patients. Compared with the runin period, fewer counselling sessions were performed in both groups (43.1\% fewer in the intervention group and $40.0 \%$ fewer in the control group), resulting in a median (IQR) difference in change between the groups of $-1.6 \%$ ( $-39.7 \%$ to $40.0 \%), p=1.0$; Table 2 ). The median duration of a counselling session was similar in both groups (10 mins in the intervention group and 11 mins in the control group, $p=0.09$ ); $51 \%$ of counselling sessions took less than 10 mins. GPs' ratings on practicability and usefulness were high for both tools (median of 4 on a 5-point Likert scale in the intervention group and 3 in the control group, $p=0.13$ and $p=0.55$, respectively). Patients motivation for smoking cessation was already high before the intervention (median 7 on a 10-point VAS) with no significant difference after the intervention $(p=0.20)$ or between groups $(p=0.73$ and $p=0.15$ before and after the intervention, respectively). Patients' ratings of the increase in motivation, self-confidence, comprehensiveness of the information, and satisfaction with the

Table 2. Comparisons of counselling and tool characteristics between groups. Results are based on 25 GPs (15 controls) and 114 counselling sessions (67 controls)

\begin{tabular}{|c|c|c|c|}
\hline Counselling and tool characteristics & $\begin{array}{l}\text { Intervention } \\
\text { Median (IQR) }\end{array}$ & $\begin{array}{l}\text { Control } \\
\text { Median (IQR) }\end{array}$ & $\mathrm{p}$ Value \\
\hline Number of counselling sessions, per month & $2.8(1.7-4.2)$ & $1.7(1.3-3.3)$ & 0.30 \\
\hline Number of counselling sessions in the run-in study period, per month & $5.5(2.3-6.0)$ & $4.0(2.5-6.0)$ & 0.72 \\
\hline $\begin{array}{l}\text { Change in number of counselling sessions from the run-in period to } \\
\text { study period, per month }\end{array}$ & $-1.9(? 3.2 ; 0.3)$ & $-1.3(-2.7 ; 0.5)$ & 0.74 \\
\hline $\begin{array}{l}\text { Change in number of counselling sessions from the run-in period to } \\
\text { study period, \% }\end{array}$ & $-43.1(-55.6 ; 17.4)$ & $-40.0(-62.5 ; 20.4)$ & 1.00 \\
\hline Duration of counseling sessions, min & $10(7-12)$ & $11(8-17)$ & 0.09 \\
\hline *Practicability, rated by GP & $4(3-4)$ & $3(2-4)$ & 0.13 \\
\hline *Usefulness, rated by GP & $4(3-4)$ & $3(2-4)$ & 0.55 \\
\hline \multicolumn{4}{|l|}{ +Patients' motivation for smoking cessation, rated by patients: } \\
\hline Before intervention & $7(5-8)$ & $7(5-8)$ & 0.73 \\
\hline After intervention & $7(5-8)$ & $7(5-9)$ & 0.15 \\
\hline Difference before and after intervention & $0(0-0)$ & $0(0-1)$ & 0.20 \\
\hline *Patients' increase in motivation, rated by patients & $4(3-4)$ & $4(3-5)$ & 0.26 \\
\hline *Self-confidence, rated by patients & $3(3-4)$ & $4(3-4)$ & 0.42 \\
\hline *Understanding of information & $5(4-5)$ & $5(5-5)$ & 0.35 \\
\hline *Satisfaction with counselling & $5(4-5)$ & $5(5-5)$ & 0.57 \\
\hline *Understanding of the tool & $4(4-5)$ & - & \\
\hline *Patients' increase in motivation by the tool, rated by patients & $4(3-4)$ & - & \\
\hline
\end{tabular}


counselling were generally high (medians 3-5 on a 5-point Likert scale). In clustered data group comparisons using Wilcoxon rank sum tests, counselling time and patient ratings remained unchanged between groups (data not shown). With regard to the visual intervention tool, comprehensiveness and increase in motivation for smoking cessation due to the tool were both rated highly (medians of 4 on a 5-point Likert scale).

\section{Discussion}

\section{Main findings}

Our main finding is that adding a visual tool with a pictorial risk message as proposed by our group is not inferior to the usual smoking cessation IPCRG tool in terms of acceptance and feasibility. In fact, the majority of GPs rated both counselling tools as equally practicable and useful. No significant differences were seen between the intervention and control groups with regard to the patients' estimates of increased motivation, self-confidence, comprehensiveness of the information, and satisfaction.

Most of the counselling activities with the pictorial intervention tool were performed within 10 mins, with no significant difference in the duration of counselling compared with the control group. This underlines the feasibility of the tool, fulfilling the criteria of a shortterm intervention.

The motivation level for smoking cessation was surprisingly high (median 7 points on a 10-point VAS), which could partially be due to selection bias at the patient level. The increase in motivation resulting from the counselling was not consistent: the item about selfestimated increase of motivation was mostly answered positively whereas the VAS measurement before and after counselling did not show a significant difference. A possible explanation is the short time between the two measurements: change of motivation as a basis for change of behaviour is often an iterative process over a long period. It is important to note that neither of the two communication tools decreased motivation in patients.

The decrease in counselling frequency during the study period compared with the run-in period is difficult to explain. Feedback from the study GPs suggests two main reasons: (1) a recall effect (the longer time since the instruction was given, the less alert were GPs about recruiting patients); and (2) many study GPs claimed a higher work load and lack of time during the study period in comparison with the run-in period. However, the decrease in counselling frequency was not significantly different between the intervention and control groups, so our tool was not the cause for less counselling activity.

Because a sharpened awareness of developing CVD can function as a strong motivator for behaviour change, ${ }^{18}$ the concept of how to communicate individualised risks for smokers versus non-smokers is highly relevant for fostering smoking cessation. We chose to communicate cardiovascular risks visually rather than respiratory risks because the absolute CVD risks (incidence) are higher than the respiratory risks, reflecting an even higher impact of the total burden of smoking-associated diseases on a patient as well as at the population level. Furthermore, the systemic effects of smoking do not only affect the respiratory system, but also the cardiovascular and other symptoms. The epidemiological evidence linking chronic obstructive pulmonary disease (COPD), for example, and cardiovascular morbidity and mortality is strong: patients with COPD have a 2-3-fold increase in the risk of cardiovascular events including death. ${ }^{19}$ In individuals with severe airways obstruction (forced expiratory volume in one second $\left(\mathrm{FEV}_{1}\right)<50 \%$ of predicted), the leading causes of death are cardiovascular in nature. ${ }^{20}$ For every $10 \%$ decrease in $\mathrm{FEV}_{1}$, cardiovascular mortality increases by about $28 \%$ and non-fatal coronary events increase by about $20 \%$ in patients with mild to moderate COPD. ${ }^{21}$

In our tool we emphasise the communication of relative risks (known to enhance the motivation to avoid risk ${ }^{11}$ ) and present it numerically and visually. To minimise the risk of manipulation of patients with the risk format, we combined information about relative risk with data on the absolute risk of a smoker. In order to facilitate decisions, we offer a comparison with a healthy (nonsmoking) reference subject. The communication of the organ (heart) age of a current smoker versus a non-smoker is another way of creating motivation by comparison of two options. ${ }^{12}$ Thus, using risk communication at the state of the art leve $\left.\right|^{9-12}$ results in positive effects in smoking cessation.

While calculating the relative risks of smokers versus non-smokers in the age group 35-65 years based on the data of a middle European cohort (PROCAM), ${ }^{15}$ we found an identical relative risk of 2 (or nearly 2) as reported from other calculators based on the Framingham cohort. Recently, the SCORE risk charts ${ }^{22}$ - which are also based on the Framingham cohort - started to communicate this relative risk of smokers versus non-smokers in addition to information on the absolute 10-year risk of a lethal cardiovascular event in the charts.

\section{Strengths and limitations of this study}

To our knowledge, this is the first randomised controlled trial (RCT) using the IPCRG smoking cessation tool as a 'usual care' standard. Moreover, the tool we developed is innovative and integrative in putting modern and evidence-based risk communication recommendations into daily practice. ${ }^{9-12}$

Our study took place in one single region of Switzerland and with a relatively small number of GPs, so the results are not generalisable without restrictions. Most of our outcomes were self-estimates and not clinical outcomes, as we had neither the intention nor the means to do a RCT of the clinical effects of the intervention but, rather, wanted to test our approach and its acceptance and feasibility. As the focus of the current study was the feasibility and acceptability of the novel counselling tool, a proper a priori sample size calculation was not possible due to the lack of reliable a priori assumptions. However, based on the 114 counselling sessions in our study, there was $80 \%$ power to detect a minimal one-sided difference of 23\% (alpha level=0.05), which almost meets the a priori non-inferiority level postulated to be clinically relevant (difference of $\geq 20 \%$ ).

We cannot exclude a selection bias due to the recruitment procedure of GPs and patients. GPs with a higher motivation for counselling activities in the field of smoking cessation might have been more prone to agree to participate and patients willing to participate might have been more motivated to start counselling than 
those who declined to participate. The high ratings of motivation (preparation stage of the TTM model) for a change at baseline might be an indicator of a possible bias. However, there was no significant difference between the intervention and control groups. We think the possible selection bias has only a small - if any - impact on our acceptance and feasibility results.

\section{Interpretation of findings in relation to previously published work}

Our findings encourage the use of both instruments in smoking cessation counselling. The IPCRG tool seems to be a well-accepted and feasible tool for short-term intervention smoking cessation counselling in Swiss primary care and merits further dissemination. Our additional tool fostering visual risk communication in order to increase motivation of smokers to quit is equally well accepted and feasible and might be an important add-on to the IPCRG tool.

The high level of acceptance of our tool may be due to the mixed communication formats we used - especially the focus on relative risks and visual elements - both of which were preferred by general practice patients. ${ }^{11}$ With regard to efficacy, the additional use of information about organ age (in our tool, heart age) is a promising way to encourage smoking cessation. Parkes et al. demonstrated an absolute difference in quit rate of $7.2 \%(13.6 \%$ in the intervention group versus $6.4 \%$ in the control group) using a similar lung age communication tool. ${ }^{12}$

\section{Implications for future research, policy and practice} Considering the immense impact of smoking cessation on patients' health and healthcare resources, it is of utmost importance to support and optimise smoking cessation counselling in primary care. Based on our results, we plan to carry out a RCT to test whether our visual risk communication tool has an additional effect on smoking cessation rates compared with the usual short intervention counselling, and whether the combination of our pictorial tool with the IPCRG tool is superior to the IPCRG tool alone.

\section{Conclusions}

In Swiss primary care, the feasibility and acceptability of both our visual smoking cessation communication tool and the IPCRG tool were equally high. Both merit further dissemination and clinical use as well as application in research.

\section{Handling editor Niels Chavannes Statistical review Gopal Netuveli}

Acknowledgements We would like to thank the study family physicians, their practice teams, and the patients for their active contribution.

Conflicts of interest The authors declare that they have no conflicts of interest in relation to this article.

Contributorship SN-J had the idea for this study. SN-J, CS-S and OS designed the study. SN-J and MIK carried out data collection. OS performed the statistical analysis. SN-J drafted the manuscript. All authors contributed to the writing of the manuscript and all authors read and approved the final manuscript.

Funding Funding was received from the Swiss Academy of Medical Sciences (SAMW). The funding agency had no role in the design process, data collection, analysis, interpretation of data, writing of the manuscript, or the decision to submit the manuscript for publication.

\section{References}

1 Center for Disease Control (CDC), Office on Smoking and Health. Data and statistics. http://www.cdc.gov/tobacco/data_statistics/index.htm

2 Anthonisen NR, Skeans MA, Wise RA, Manfreda J, Kanner RE, Connett JE. The effects of a smoking cessation intervention on 14.5-year mortality. Ann Intern Med 2005;142:233-9.

3 Doll R, Peto R, Wheatley K, Gray R, Sutherland I. Mortality in relation to smoking. 50 years observation on male British doctors. BMJ 1994;309:901-11. http://dx.doi.org/10.1136/bmj.309.6959.901

4 Jha P, Chaloupka FJ, Corrao M, Jacob B. Reducing the burden of smoking worldwide: effectiveness of interventions and their coverage. Drug A/cohol Rev 2006;25(6):597-609. http://dx.doi.org/10.1080/09595230600944511

5 Tabakmonitoring Schweiz. http://www.tabakmonitoring.ch

6 Prochaska JO, DiClemente CC. Stages and processes of self-change of smoking: toward an integrative model of change. J Consult Clin Psychol 1983;51:390-5. http://dx.doi.org/10.1037/0022-006X.51.3.390

7 Haug S, Meyer C, Ulbricht S, et al. Predictors and moderators of outcome in different brief interventions for smoking cessation in general medical practice. Patient Educ Couns 2010;78:57-64. http://dx.doi.org/10.1016/j.pec.2009.07.005

8 Stead LF, Bergon G, Lancester T. Physician advice for smoking cessation (Review). The Cochrane Library 2008;(4):CD000165.

9 Hill S, Spink J, Cadilhac D, et al. Absolute risk representation in cardiovascular disease prevention: comprehension and preferences of health care consumers and general practitioners involved in a focus group study. BMC Public Health 2010;10:108. http://dx.doi.org/10.1186/1471-2458-10-108

10 Lipkus IM. Numeric, verbal and visual formats of conveying health risks: suggested best practices and future recommendations. Med Decis Making 2007;27:696-713. http://dx.doi.org/10.1177/0272989X07307271

11 Goodyear-Smith F, Kenealy T, Wells S, Arroll B, Horsburgh M. Patients' preference for ways to communicate benefits of cardiovascular medication. Ann Fam Med 2011;9:121-7. http://dx.doi.org/10.1370/afm.1193

12 Parkes G, Greenhalgh T, Griffin M, Dent R. Effect on smoking quit rate of telling patients their lung age: the Step2quit randomised controlled trial. BMJ 2008;336:598-600. http://dx.doi.org/10.1136/bmj.39503.582396.25

13 International Primary Care Respiratory Group. Helping patients quit smoking: brief interventions for healthcare professionals. http://www.theipcrg.org/resources

14 Battegay E, Noseda G, Riesen W. Atherosklereose-Prävention. Verlag Hans Huber, Hogrefe AG, Bern, 2007.

15 Assmann $G$, Schulte $H$, Cullen $P$, Seedorf U. Assessing risk of myocardial infarction and stroke: new data from the Prospective Cardiovascular Münster (PROCAM) study. Eur J Clin Invest 2007:37(12):925-32. http://dx.doi.org/10.1111/j.1365-2362.2007.01888.x

16 Achermann-Liebrich U, Kuna-Dibbert B, Probst-Hensch N, et al., for the SAPAPLDIA team. Follow-up of the Swiss Cohort Study on Air Pollution and Lung Diseases in Adults (SAPALDIA 2) 1991-2003: methods and characterization of partizipants. Soz Präventivmed 2005;50:245-63. http://dx.doi.org/10.1007/s00038-005-4075-5

17 Rosner B, Glynn RJ, Lee MLT. Extension of the rank sum test for clustered data: twogroup comparisons with group membership de?ned at the subunit level. Biometrics 2006;62:1251-9. http://dx.doi.org/10.1111/j.1541-0420.2006.00582.x

18 Galbraith EM, Mehta PK, Veledar E, Vaccarino V, Wenger NK. Women and heart disease: knowledge, worry, and motivation. J Womens Health 2011;20(10):152934. http://dx.doi.org/10.1089/jwh.2010.2356

19 Curkendall SM, DeLuise C, Jones JK, et al. Cardiovascular disease in patients with chronic obstructive pulmonary disease, Saskatchewan Canada cardiovascular disease in COPD patients. Ann Epidemiol 2006;16(1):63-70. http://dx.doi.org/10.1016/j.annepidem.2005.04.008

20 Sin DD, Anthonisen NR, Soriano JB, Agusti AG. Mortality in COPD: role of comorbidities. Eur Respir J 2006;28(6):1245-57. http://dx.doi.org/10.1183/09031936.00133805

21 Sin DD, Man PSF. Chronic obstructive pulmonary disease is a risk factor for cardiovascular morbidity and mortality. Proc Am Thorac Soc 2005;2:8-11. http://dx.doi.org/10.1513/pats.200404-032MS

22 European Society of Cardiology. The SCORE risk charts. http://www.escardio.org/ communities/EACPR/toolbox

\section{Available online at http://www.thepcrj.org}




\section{What does your patient win by quitting smoking?}

\section{The risk of the patient to suffer a heart attack or stroke in the next 10 years time is:}

as a women

\begin{tabular}{|c|c|c|}
\hline age & $\begin{array}{l}\text { 10-y-risk as } \\
\text { a smoker }\end{array}$ & $\begin{array}{l}\text { 10-y-lisk as } \\
\text { a non-smoker }\end{array}$ \\
\hline$\geq 65$ & 10.6 & 5.7 \\
\hline 64 & 9.6 & 5.2 \\
\hline 63 & 8.7 & 4.7 \\
\hline 62 & 7.9 & 4.2 \\
\hline 61 & 7.2 & 3.8 \\
\hline 60 & 65 & 3.5 \\
\hline 59 & 5.9 & 3.1 \\
\hline 58 & 5.4 & 2.8 \\
\hline 57 & 4.9 & 2.6 \\
\hline 56 & 4.4 & 2.3 \\
\hline 55 & 4 & 2.1 \\
\hline 54 & 3.6 & 1.9 \\
\hline 53 & 3.3 & 1.7 \\
\hline 52 & 2.9 & 1.5 \\
\hline 51 & 2.7 & 1.4 \\
\hline 50 & 2.4 & 1.3 \\
\hline 49 & 05 & 0.3 \\
\hline 48 & 05 & 0.3 \\
\hline 47 & 0.4 & 0.2 \\
\hline 46 & 0.4 & 0.2 \\
\hline 45 & 0.4 & 0.2 \\
\hline 44 & 0.3 & 0.2 \\
\hline 43 & 0.3 & 0.2 \\
\hline 42 & 0.3 & 0.1 \\
\hline 41 & 0.2 & 0.1 \\
\hline 40 & 0.2 & 0.1 \\
\hline 39 & 0.2 & 0.1 \\
\hline 38 & 0.2 & 0.1 \\
\hline 37 & 0.2 & 0.1 \\
\hline 36 & 0.1 & $0.1^{3}$ \\
\hline s石 & 0.1 & $0.1^{3}$ \\
\hline
\end{tabular}

as a man

\begin{tabular}{|c|c|c|}
\hline asc & $\begin{array}{l}\text { 10-y-risk as } \\
\text { a smoker }\end{array}$ & $\begin{array}{l}\text { 10-y-risk as } \\
\text { a non-smoker }\end{array}$ \\
\hline 265 & 21.6 & 12.2 \\
\hline 64 & 19.8 & 11.1 \\
\hline 63 & 18.1 & 10.1 \\
\hline 62 & 16.6 & 9.2 \\
\hline 61 & 15.2 & 8.3 \\
\hline 60 & 13.8 & 7.5 \\
\hline 59 & 12.6 & 6.8 \\
\hline 58 & 11.5 & 6.2 \\
\hline 57 & 10.5 & 5.6 \\
\hline 56 & 95 & 5.1 \\
\hline 55 & 8.6 & 4.6 \\
\hline 54 & 78 & 4.2 \\
\hline 53 & 7.1 & 3.8 \\
\hline 52 & 65 & 3.4 \\
\hline 51 & 58 & 3.1 \\
\hline 50 & 5.3 & 2.8 \\
\hline 49 & 48 & 2.5 \\
\hline 48 & 4.3 & 2.3 \\
\hline 47 & 3.9 & 2.1 \\
\hline 46 & 3.6 & 1.9 \\
\hline 45 & 3.2 & 1.7 \\
\hline 44 & 2.9 & 1.5 \\
\hline 43 & 2.6 & 1.4 \\
\hline 42 & 2.4 & 1.2 \\
\hline 41 & 2.1 & 1.1 \\
\hline 40 & 1.9 & 1.0 \\
\hline 39 & 18 & 0.9 \\
\hline 38 & 1.6 & 0.8 \\
\hline 37 & 1.4 & 0.7 \\
\hline 36 & 1.3 & 0.7 \\
\hline$\leqq 35$ & 1.2 & 0.6 \\
\hline
\end{tabular}

Comments:

Blo oll pressure anl lipils (tota l ch olesterol, trintycerill es, HDL, LDL) refer to the averane values of the Su iss SAPALDIA

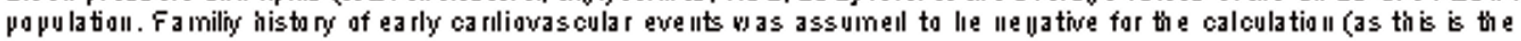

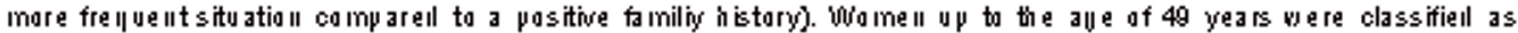

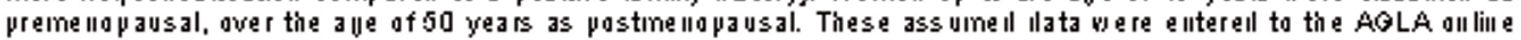

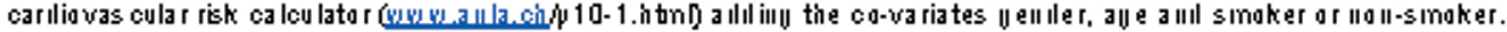

"The relative risk of s mokers versus $\|$ oll-s mokers is a linost 2 in all a

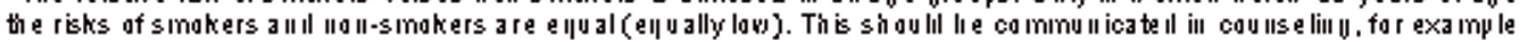

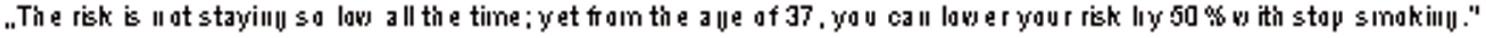

Copright: Institute of General Practice and Health Service Research Zürich, Switzerland 


\section{What do I win by quitting smoking?}

my risk

If I continue to smoke, my risk to get a heart attack or stroke within the next 10 years is $\%$ ('l out of ).

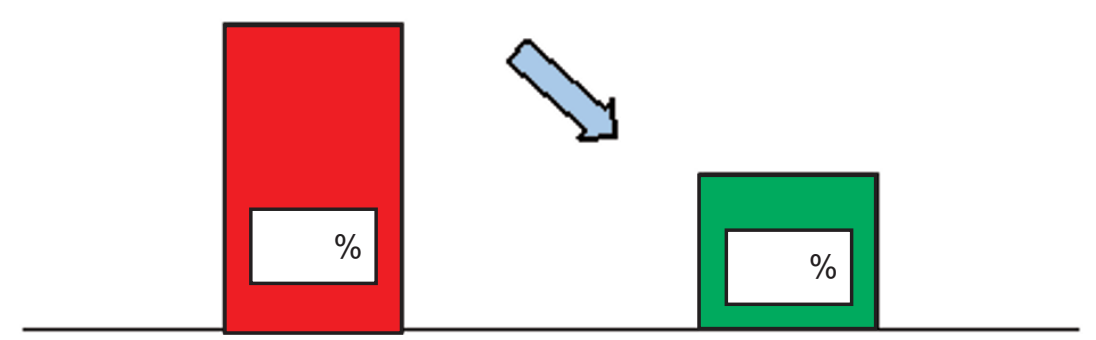

\author{
my risk as \\ a non-smoker
}

With quitting smoking right now, I lower my risk by almost $50 \%$ (from $\%$ to $\%$ ) compared with going on with smoking.

In my age, the risk to get a heart attack or stroke within the next 10 years is equal to the risk of $a$ years old non-smoker!

If I have olovated blood pressure, lipid (oholester ol) of blood sugar values, the risks a higher than the above montioned values. By quitting smoking, the risk will be half in comparison to going on with smoking as well. I also lower further lisks substantially, suoh as lung oanoer or ohronio bronohitis with quitting smoking.

Copyright: Institute of General Practice and Health Service Research Zürich, Switzerland 
Appendix 3. IPCRG Opinion sheet for stop smoking (in english)

\section{OPINION}

\section{Helping patients quit smoking: brief interventions for healthcare professionals}

\section{How to help simolese quit: flowchart}

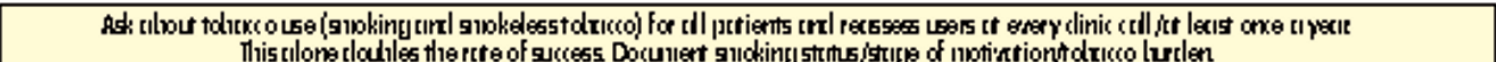

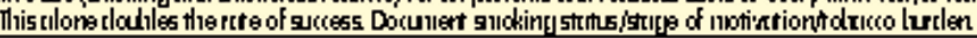

ASK Htreycu usecltdIxcointlelest 12 mortlø?

\begin{tabular}{|c|c|}
\hline 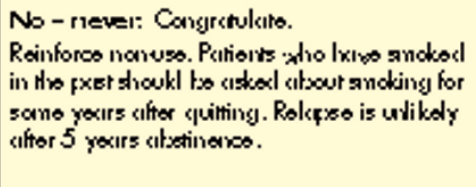 & 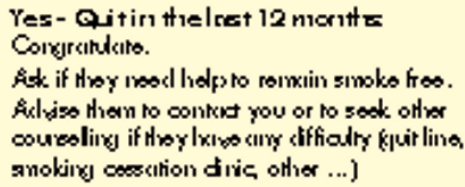 \\
\hline
\end{tabular}

\begin{tabular}{|c|}
\hline 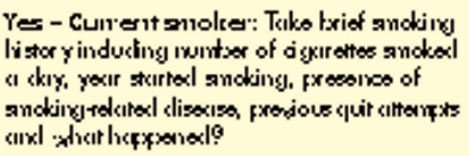 \\
\hline 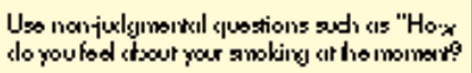 \\
\hline 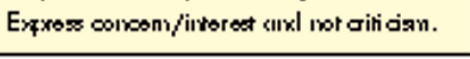 \\
\hline
\end{tabular}

ASSESS: Matixdoun batax

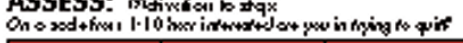

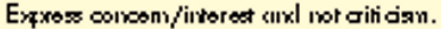

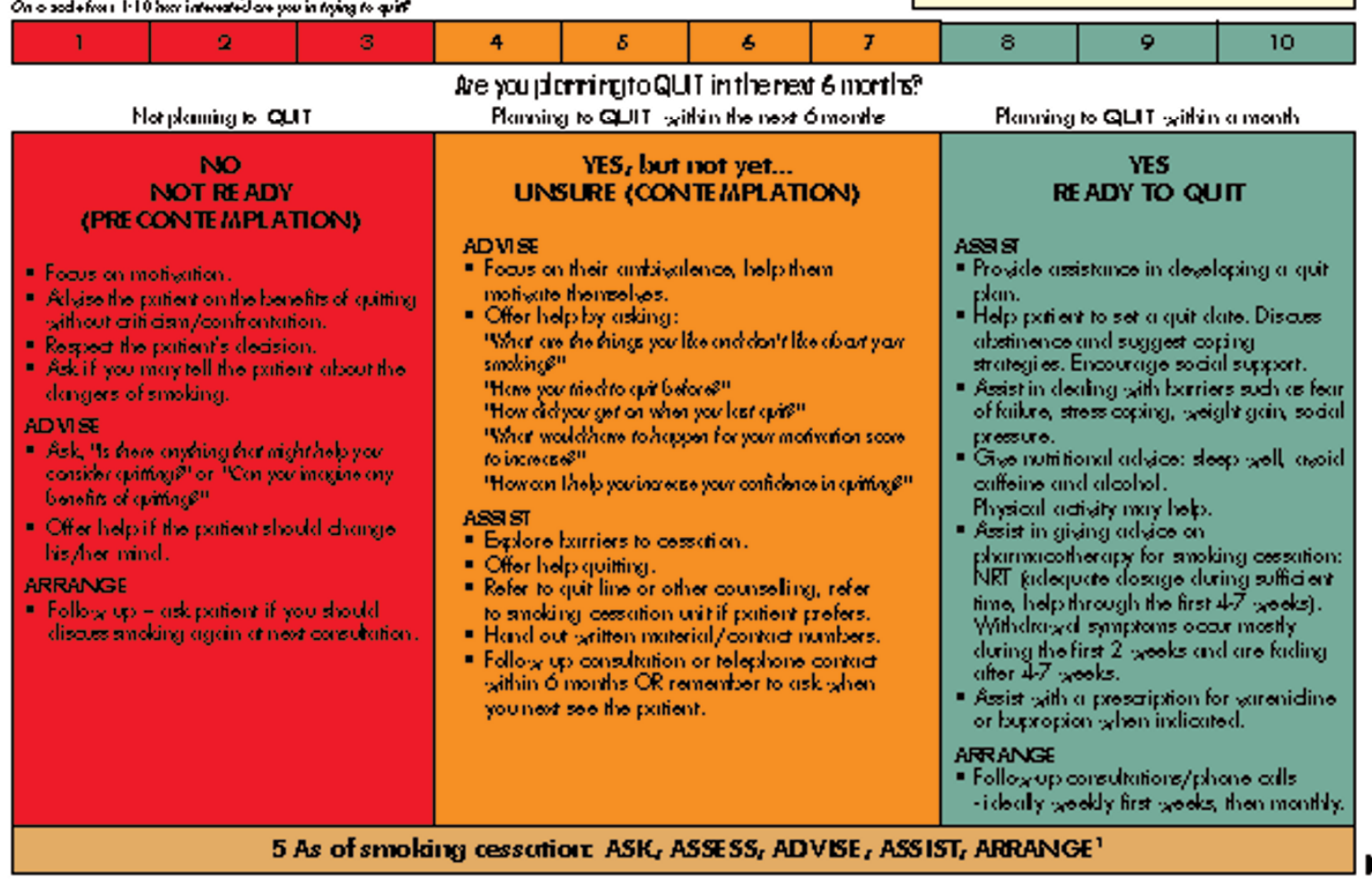

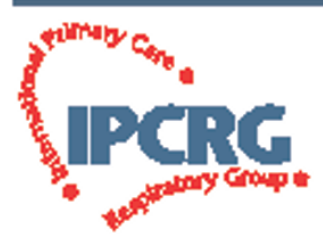

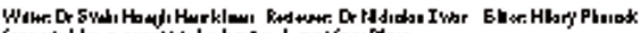

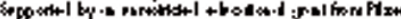

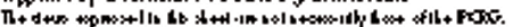

Loc

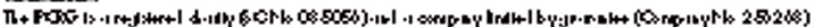

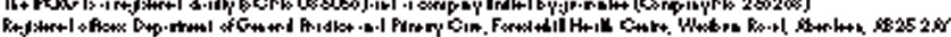




\section{Appendix 4. VISTO pilot study - CONSORT 2010 checklist of information to include when reporting a randomised} trial*

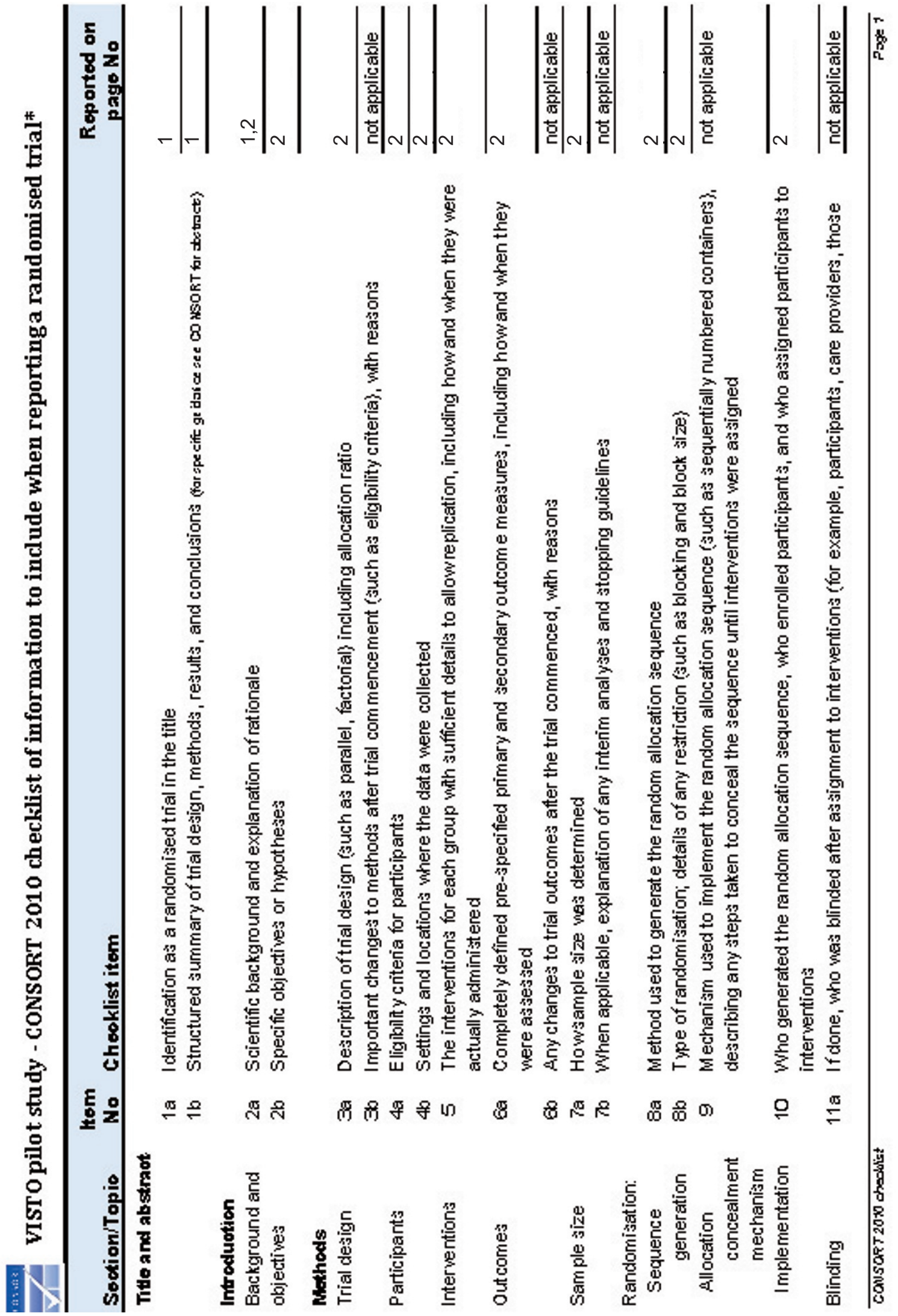




\section{Appendix 4. VISTO pilot study - CONSORT 2010 checklist of information to include when reporting a randomised} trial* continued
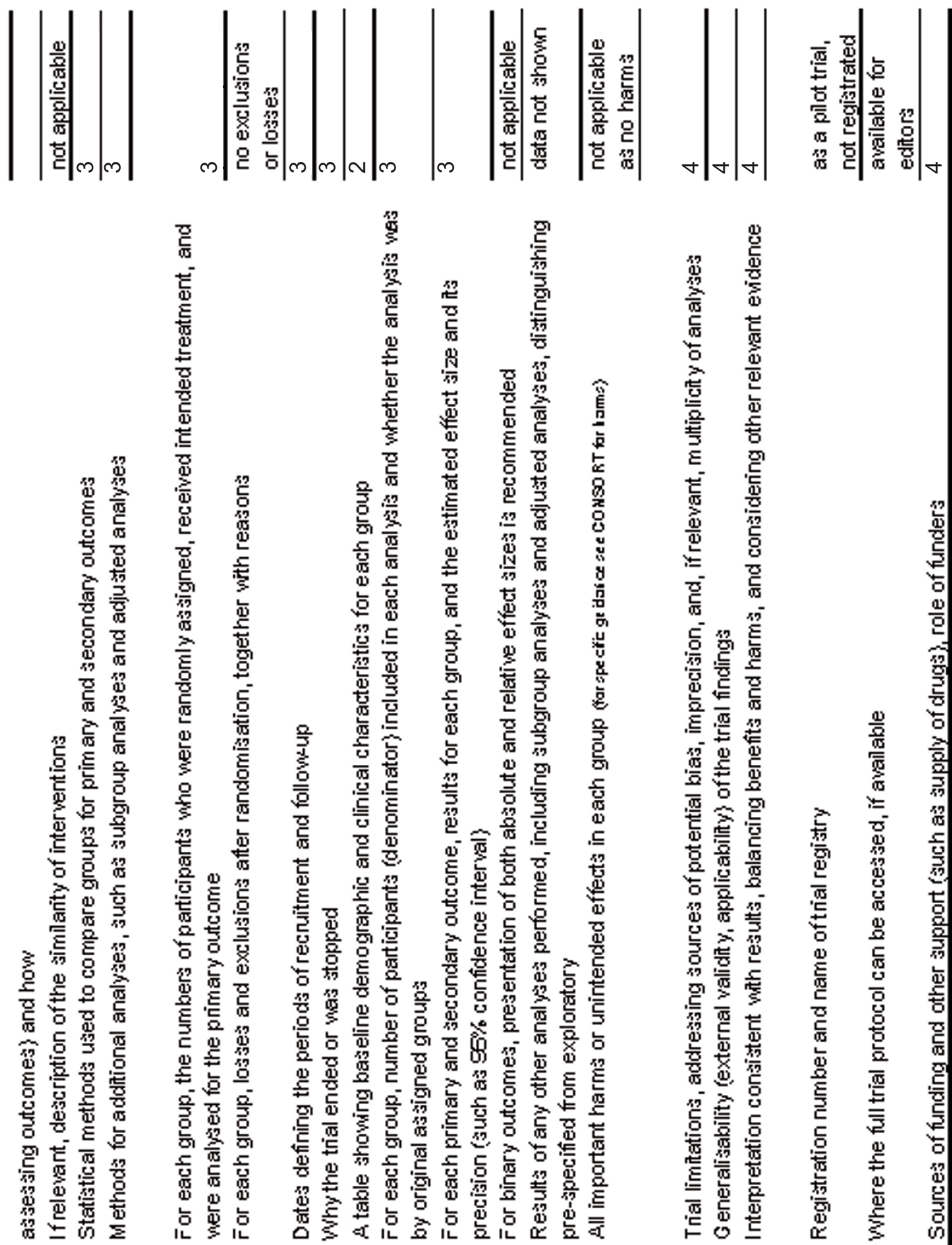

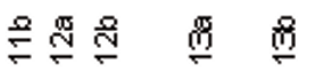

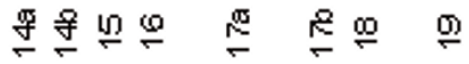

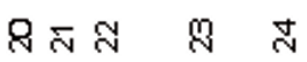
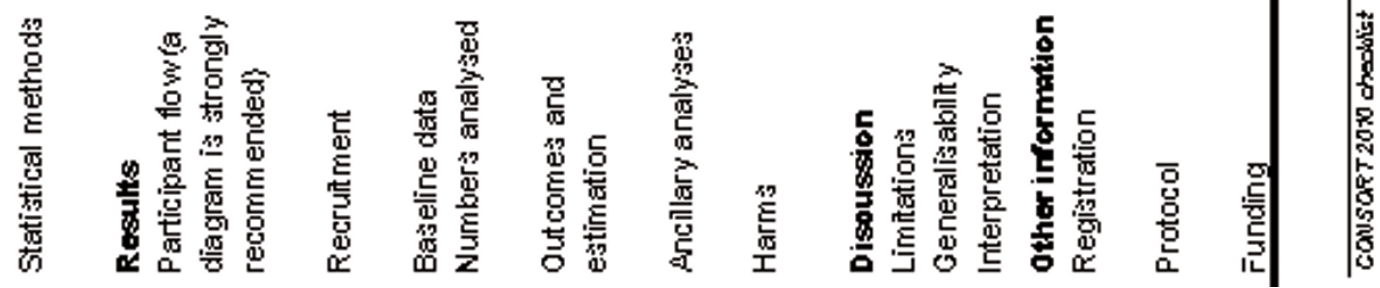

PRIMARY CARE RESPIRATORY JOURNAL 